\title{
PERAN KEPALA SEKOLAH DALAM MENINGKATKAN MUTU PENDIDIKAN SMA NEGERI DI KECAMATAN RUMBIO JAYA KABUPATEN KAMPAR PROVINSI RIAU
}

\author{
Aris Suhud 1) \\ Jimmi Copriady ${ }^{2}$ \\ Isjoni $^{3)}$ \\ 1) Post Graduate Student of Riau University \\ 2) Lecturer of Education Management Study Programme PPs University of Riau \\ ${ }^{3)}$ Lecturer of Education Management Study Programme PPs University of Riau
}

\begin{abstract}
This study aims to determine the role of school principals in improving the quality of education of public high schools in Rumbio Jaya District, Kampar Regency, Riau Province by analyzing the roles of school principals as educators, managers, administrators, supervisors, leaders, innovators and motivators. The research was conducted in October 2017 - February 2018 at SMA Negeri 01 and 02, District of Rumbio Jaya. This research is a type of qualitative research because the subjects under study are people with all their activities and their natural surroundings. The data collection method is done through observation, documentation and interviews. The data validation used the triangulation method. Data were analyzed with qualitative analysis from Miles and Huberman, namely through 3 steps of activity, namely data reduction, data presentation and drawing conclusions. The results showed that the principal of the State Senior High School in Rumbio Jaya Subdistrict, Kampar Regency, Riau Province had carried out his duties as an educator, manager, administrator, supervisor, leader, innovator and motivator. Overall, the role of the principal of the State Senior High School in Rumbio Jaya Subdistrict, Kampar Regency, Riau Province is very important in implementing educational activities in an effort to improve the quality of education. The role of the school principal as a leader and an innovator is what differentiates the achievement in improving the quality of education at public high schools in Rumbio Jaya sub-district, Kampar district, Riau province.
\end{abstract}

Keywords: Role of the Principal, Quality of Education 


\begin{abstract}
ABSTRAK
Penelitian ini bertujuan untuk mengetahui peran kepala sekolah dalam meningkatkan mutu pendididkan SMA Negeri di Kecamatan Rumbio Jaya Kabupaten Kampar Provinsi Riau dengan menganalisis peran kepala sekolah sebagai edukator, manajer, administrastor, supervisor, leader, inovator maupun motivator. Penelitian dilakukan pada bulan oktober 2017 - Febuari 2018 di SMA Negeri 01 dan 02 Kecamatan Rumbio Jaya. Penelitian ini merupakan jenis penelitian kualitatif karena subjek yang diteliti adalah orang dengan segala aktivitasnya dan alam sekitarnya. Metode pengumpulan data dilakukan melalui observasi, dokumentasi dan wawancara. Validasi data menggunakan metode trianggulasi. Data dianalisis dengan analisis kualitatif dari Miles dan Huberman, yakni melalui 3 langkah kegiatan yaitu reduksi data, penyajian data dan penarikan kesimpulan. Hasil penelitian menunjukkan bahwa kepala sekolah SMA Negeri di Kecamatan Rumbio Jaya Kabupaten Kampar Provinsi Riau telah melaksanakan tugasnya sebagai edukator, manajer, administrastor, supervisor, leader, inovator maupun motivator. Peran kepala sekolah SMA Negeri di Kecamatan Rumbio Jaya Kabupaten Kampar Provinsi Riau tersebut secara keseluruhan sangat mewarnai pelaksanaan kegiatan pendidikan dalam upaya meningkatkan mutu pendidikan. Peran kepala sekolah sebagai leader dan inivator merupakan pembeda pencapaian dalam meningkatkan mutu pendidikan pada SMA Negeri di Kecamatan Rumbio Jaya Kabupaten Kampar Provinsi Riau.
\end{abstract}

Kata Kunci : Peran Kepala Sekolah, Mutu Pendidikan.

\section{PENDAHULUAN}

Merosotnya mutu pendidikan disebabkan karena sistem pendidikan di Indonesia selama ini terlihat lebih cenderung terpokus pada input pendidikan dan prosesnya (Jahya Umar 2005). Selain itu, realitas kemorosotan pendidikan sekolah sekarang juga disebabkan oleh mayoritas kepala sekolah yang masih belum memiliki kualitas dan kompetensi yang memadai dalam menjalankan perannya sebagai kepala sekolah serta pemahaman kepala sekolah yang rendah terhadap visi dan misi sekolah yang dipimpinnya atau bahkan kepala sekolah tidak tahu apa visi sekolah dan tidak memahami benar arti visi dan misi sekolah serta bagaimana mewujudkan visi itu.

Salah satu upaya meningkatkan mutu pendidikan yaitu dengan melakukan pemberdayaan terhadap kepala sekolah, karena kepala sekolah merupakan motor penggerak bagi sumber daya sekolah terutama guruguru dan karyawan sekolah. Besarnya peran kepala sekolah dalam proses pencapaian tujuan pendidikan, sehingga dapat dikatakan bahwa sukses tidaknya kegiatan sekolah sebagian besar ditentukan oleh kualitas kepala sekolah itu sendiri. Problematika pendidikan mengisyaratkan perlunya penerapan kepemimpinan pendidikan oleh seorang kepala sekolah. Kepala sekolah adalah pemimpin pendidikan yang mempunyai peran sangat besar dalam mengembangkan mutu pendidikan di sekolah. Kepala sekolah harus yakin bahwa anggota sekolahnya memerlukan standar, harapan dan kinerja bermutu tinggi. Kepala sekolah juga harus yakin bahwa visi sekolah harus menekankan standar pelajaran yang tinggi dan 
perlunya menempuh resiko yang nalar untuk meningkatkan mutu sekolahnya dengan menggunakan pengaruh jabatan secara produktif untuk melayani peserta didik dan keluarganya, (Agus Darma, 2003).

Departemen Pendidikan dan Kebudayaan, menerangkan bahwa fungsi utama kepala sekolah sebagai pemimpin pendidikan ialah menciptakan situasi belajar mengajar sehingga guru-guru dapat mengajar dan para siswa dapat belajar dengan baik. Menurut (E. Mulyasa. 2007) bahwa dalam perkembangan selanjutnya sesuai kebutuhan masyarakat dan perkembangan zaman serta adanya paradigma baru manajemen pendidikan, kepala sekolah harus mampu berfungsi (berperan) sebagai educator, manajer, administrator, supervisor, leader, innovator, motivator (EMASLIM).

Dalam prespektif kebijakan pendidikan nasional (Depdiknas, 2006), terdapat tujuh peran utama kepala sekolah yaitu sebagai: Educator (Pendidik), manajer; administrator; supervisor (penyelia), leader (pemimpin), pencipta iklim kerja dan wirausahawan. Dalam perkembangan selanjutnya, sesuai dengan kebutuhan masyarakat dan perkembangan zaman, maka kepala sekolah memiliki tujuh peran yaitu: sebagai Edukator; manajer; administrator; supervisor; leader; innovator, motivator (EMASLIM).

Keberhasilan sekolah banyak ditentukan oleh kapasitas kepala sekolahnya di samping adanya guruguru yang kompeten di sekolah itu (Danim, 2004:145). Kepemimpinan kepala sekolah yang efektif diterima secara luas sebagai komponen kunci untuk terwujudnya pembenahan mutu sekolah. Mutu kepala sekolah berdampak terhadap motivasi jajarannya dan mutu pembelajaran di kelas (Hartle \& Thomas, 2003 : 54).

Kepemimpinan kepala sekolah dirasa perlunya untuk selalau ditingkatan secara profesional untuk mensukseskan program-program pemerintah yang digulirkan berkaitan dengan peningkatan mutu pendidikan. Kepala sekolah harus tahu apa yang harus dicapai (visi) dan bagaimana mencapainya (misi). Kepala sekolah harus memiliki peran yang menunjukkan integritas sebagai pemimpin suatu sekolah yang profesional. Segala bentuk kegiatan sekolah selalu diarahkan pada peningkatan profesionalisme tenaga kependidikan untuk meningkatkan mutu pendidikan agar dapat berkembang dan maju sesuai dengan kebutuhan pembangunan dan perkembangan zaman. SMA Negeri di Kecamatan Rumbio Jaya sebagai lembaga pendidikan yang cukup baik dan tergolong baru di daerah kabupaten kampar, yang sudah berupaya menjaga dan meningkatkan kualitas/mutu pendidikannya dengan meningkatkan dan menorehkan prestasi, walaupun kepala sekolah SMA N 2 Rumbio Jaya nya diangkat dan ditunjuk secara formalitas oleh pimpinan daerah dan baru berumur baru empat tahun akan tetapi kepala sekolah tersebut bisa membuat sekolah tersebut beberapa prestasi dan diperhitungkan di kabupaten Kampar, berbeda dengan SMA N 1 Rumbio Jaya yang notabendnya lebih lama berdiri dan lebih memiliki banyak murid tetapi tidak menunjukkan peningkatan prestasi yang signifikan yang dapat kita lihad dari prestasi yang ditorehkan selama ini.

Tujuan dari penelitian ini adalah sebagai untuk mengetahui peran apa saja yang telah di lakukan Kepala Sekolah dalam meningkatkan mutu pendidikan pada SMA Negeri di 
Kecamatan Rumbio Jaya Kabupaten Kampar Riau dan untuk mengetahui hambatan apa saja yang dihadapi Kepala Sekolah dalam melaksakan perannya sebagai educator, manajer, administrator, supervisor, leader, innovator dan motivator untuk meningkatkan mutu pendidikan pada SMA Negeri di Kecamatan Rumbio Jaya Kabupaten Kampar.

\section{METODOLOGI PENELITIAN}

Metode yang digunakan dalam penelitian ini adalah pendekatan kualitatif. Penelitian kualitatif (qualitative research) adalah sebuah tipe penelitian yang mengandalkan pandangan para partisipan, mengajukan pertanyaan yang bersifat umum dan luas, mengumpulkan data-data yang sebagian besar terdiri dari kata-kata ini kedalam tema-tema, dan melaksanakan penelitian yang tidak bisa bebas dari rasa subjektivitas dan bias.

Data penelitian yang dikumpulkan berbentuk naratif, meskipun tidak menutupi kemungkinan data berupa angka-angka, namun tidak bermaksud memverifikasi data tersebut. Data yang dimaksudkan dalam penelitian ini adalah bagaimana kepala sekolah melakukan perannya dalam meningkatkan mutu pendidikan SMA Negeri di Kecamatan Rumbio Jaya, yang berkaitan dengan Edukator (Pemimpin); Manajer (Pengelola); Administrator (pengatur atau pemerdaya guna); Supervisor (pengawasan dan pengadili); leader (pemimpin); Innovator (pencipta iklim kerja). Motivator (pemberi semangat).

Sumber data dalam penelitian ini ada dua, yaitu data primer dan skunder. Data primer adalah data yang lansung dikumpulkan oleh peneliti melalui objek penelitian yaitu kepala sekolah, guru dan tatausaha. Data sekunder adalah data yang diperoleh dari dokumen yang ada dan relevan dengan masalah penelitian, data sekunder yang diperoleh dari sekolah dan komite sekolah juga bisa orang di ruang lingkup sekolah tentang peranan kepala sekolah dalam meningkatkan mutu pendidikan SMA Negeri di Kecamatan Rumbio Jaya.

Analisis data dalam penelitian ini dilakukan pada saat pengumpulan data berlangsung, dan setelah selesai pengumpulan data dalam periode tertentu. Pada saat wawancara, peneliti sudah melakukan analisis terhadap jawaban yang diwawancarai. Bila jawaban yang diwawancarai setelah dianalisis terasa belum memuaskan, maka peneliti akan melanjutkan pertanyaan lagi, sampai tahap tertentu, diperoleh data yang dianggap kredibel. Miles dan Huberman (1984), mengemukakan bahwa aktivitas dalam analisis data kualitatif dilakukan secara interaktif dan berlangsung secara terus menerus sampai tuntas, sehingga datanya sudah jenuh. Aktivitas dalam analisis data, yaitu data reduction, data display, dan conclusion drawing/ verification.

\section{HASIL PENELITIAN DAN PEMBAHASAN}

Kepala SMA Negeri di Rumbio Jaya sebagai pendidik (edukator) sudah mampu membimbing, membina dan menyamakan persepsi seluruh guru dan tenaga kependidikan serta siswa. Kepala SMA Negeri di Rumbio Jaya senantiasa membimbing dan membina guru, staf, tata usaha serta siswa. Kepala sekolah juga telah membuat membuat program pengajaran dan melaksanakan kegiatan belajar mengajar di hadapan para peserta didik sebagaimana seorang guru mata pelajaran lainnya yang dibuktikan dari program pembelajaran yang telah disusunnya dan pembagian tugas belajar dengan surat keputusan nomor 
421.3/SMAN 1/ RJ/1964, untuk SMA Negeri 01 Rumbio Jaya dan surat nomor : 422/SMAN2RJ/2017/556, untuk SMA Negeri 02 Rumbio Jaya. Mata pelajaran yang diampu oleh kepala sekolah tetap mengacu kepada spesialisasi yang telah dimilikinyai, jumlah jam wajib 6 jam setiap minggu juga dipenuhi oleh kepala sekolah, selain kegiatan mengajar kepala sekolah mengembangkan kemampuan untuk membimbing, mendidik para siswa, guru dan tenaga, kependidikan . Dengan pendidikan yang ia berikan kepada guru dan tenaga kependidikan mampu menjalankan tugas dan fungsinya secara maksimal. kepala SMA Negeri di Rumbio Jaya sudah melaksanakan perannya sebagai edukator, baik edukator bagi pendidik, tenaga kependidikan dan siswa. Kegiatan yang dilakukan kepala sekolah kesemuanya itu dilakukan dalam rangka upaya meningkatkan mutu pendidikan yang menjadi tujuan akhir dari pendidikan yang bermutu dan berkualitas.

Kepala SMA Negeri di Rumbio Jaya sebagai manajer sudah memiliki program dan target yang harus diwujudkan selama masa jabatan kepemimpinannya. kepala SMA Negeri di Rumbio Jaya selalu berupaya mengelola sumber daya pendidikan untuk mencapai misi dan tujuan sekolahnya masing-masing. Dalam melaksanakan tugasnya sebagai manajer kepala SMA Negeri di Rumbio Jaya telah menjalankan fungsi-fungsi manajemen atau pengelolaan yang meliputi: perencanaan, pengorganisasian, dan pengendalian. Kepala sekolah juga telah melaksanakan inovasi dalam berbagai bidang administrasi. Dalam pelaksanaan peran sebagai manejer kepala SMA Negeri di Rumbio Jaya berpegang pada prinsipprinsip manajerial, seperti : pembagian kerja yang transparan, pemberian wewenang dan tugas, kesatuan perintah, kesatuan kerja, disiplin, mendahulukan kepentingan sekolah dari pada kepentingan individu, penghargaan dan sanksi, inisiatif, efektivitas dan efisiensi, dan keterpaduan, hal ini dibuktikan dengan surat keputusan kepala sekolah SMA Negeri 01 Rumbio Jaya nomor : 421.3/SMAN 1/RJ/1964 untuk tugas pengajaran, nomor : 421.3/SMAN 1/RJ/1965 untuk tugas satuan kerja piket sekolah, nomor : 421.3/SMAN 1/RJ/1964 untuk tugas terobosan, nomor : 421.3/SMAN 1/RJ/1927 untuk tenaga administrasi sekolah, nomor : 421.3/SMAN 1/RJ/1683 untuk tugas pendelegasian. Sedangkan untuk manejerial kepala sekolah SMA Negeri 02 Rumbio Jaya mengeluarkan surat keputusan nomor : 422/SMAN2-RJ/2017/556 untuk pembaguan tugas mengajar, nomor : 422/SMAN2-RJ/2017/697 untuk pembagian tugas piket harian, nomor : 420/SMAN2-RJ/I/2018/719 untuk pembagian tugas supervise dan pembantu supervise, nomor : 422/SMAN2-RJ/2017/530 untuk pembagian tugas tatusaha, nomor : 422/SMAN2-RJ/2016/117 dan 422/SMAN2-RJ/2017/396 untuk pembaguan tugas pendelegasian. Kepala SMA Negeri di Kecamatan Rumbio Jaya dalam melaksankan perannya sebagai seorang manajer telah melaksanakan prinsip pembagian kerja yang teratur dan mendelegasikan tugas dan wewenangnya kepada para pembantu-pembantunya seperti kepala tata usaha, kepala urusan yang menangani berbagai bidang kegiatan maupun personil lainnya dalam bentuk struktur organisasi program sekolah untuk mencapai tujuan yang telah ditetapkan, juga melakukan pengawasan dan evaluasi terhadap kinerja seluruh stafnya. 
Kepala SMA Negeri di Rumbio Jaya sebagai administrator berupaya untuk memberikan penekanan kepada para guru dan pegawai secara umum untuk melaksanakan tata administrasi yang baik sesuai dengan bidangnya masing-masing dalam rangka memperlancar pelaksanaan tugas dan tanggungjawabnya dalam bekerja. Kepala SMA Negeri di Rumbio Jaya member wewenang penuh dalam tugas dan kewenangan tata usaha sebagai pembantu utama kepala sekolah dalam hal administrasi, selain menangani tentang pengarsipan administrasi belajar mengajar juga menangani berbagai kegaiatan administrasi sekolah secara umum. Masalah yang berkaitan dengan kenaikan pangkat dan administrasi kepangkatan SMA Negeri 01 Rumbio Jaya telah melakukan proses dengan baik tanpa ada kendala dan complain dari para guru walaupun kmepala sekolah memahami betul akan keterbatasan ilmu dan keprofesionalan kepala tatausaha, senada halnya pada SMA Negeri 02 Rumbio Jaya mengalami kendala dalam pengurusan kepangkatan dan administrasi kepangkatan para guru, hal yang menyebabkan terjadinya kesenjangan di SMA Negeri 02 Rumbio Jaya dalam kepangkatan disebabkan oleh tenaga tata usaha yang belum mahir, profesional dan belum berpengalaman, akan tetapi kepala sekolah selalu berupaya dengan sebaikmungkin mengatasi masalah tersebut dengan minta bantuan kerelasi sekolah dalam penyelesaian administrasi, sehingga terciptanya kenyamanan dalam pebgurusan administrasi. Seorang kepala sekolah menjadi sentral bagi kegiatan administrasi di sekolah, sehingga sebagai administrator kepala sekolah memiliki dua kegiatan utama, yaitu sebagai pengendali struktur organisasi dan melaksanakan administrasi substantif. Sebagai pengendali struktur organisasi kepala sekolah SMA Negeri di Kecamatan Rumbio Jaya telah memahami bagaimana membuat laporan, dengan siapa tugas tersebut dipertanggungjawabkan, dan dengan siapa ia harus bekerja dan berinteraksi. Sebagai pelaksana administrasi substantif, kepala sekolah SMA Negeri di Kecamatan Rumbio Jaya telah menguasai administrasi kurikulum, kesiswaan, personalia, keuangan, sarana dan prasarana, humas dan administrasi umum lainnya.

Kepala SMA Negeri di Rumbio Jaya telah melaksanakan supervisi untuk memantau tenaga kependidikan agar tercapai proses belajar mengajar yang lebih baik hal ini dibuktikan dengan surat keputusan kepala sekolah SMA Negeri 01 Rumbio Jaya yang terlampir atas dasar mupakat rapat yang ditetapkan tanggal 24 Agustus 2017, sedangkan proses supervisi SMA Negeri 02 Rumbio Jaya tercantum dalam surat keputusan nomor : 420/SMAN-RJ/I/2018/719. Supervisi yang dilakukan oleh kepala SMA Negeri di Rumbio Jaya sebagai salah satu bentuk pembinaan kepada guru untuk meningkatkan kemampuan dalam kegiatan proses belajar mengajar, bukan untuk mencari kesalahan dan kelemahan guru, sehingga jika terdapat kelemahan guru dalam kegiatan proses belajar mengajar dapat disarankan untuk diperbaiki demi peningkatan mutu yang menjadi prioritas pertama di sekolah masing-masing, sebaliknya guru juga mendapatkan dan pembinaan kepala sekolah karena terdapat kelemahan guru dalam mengajar, itu semua adalah hal yang wajar dalam guru mengajar untuk mencapai mutu pendidikan dan harapan masyarakat agar dapat terpenuhi. Supervisi oleh kepala SMA Negeri di Rumbio Jaya berupa bentuk pelayanan, bantuan profesional, atau bimbingan 
bagi guru-guru agar mampu meningkatkan mutu pendidikan dan pengajaran. Dari berbagai pernyataan dan uraian diatas, dapat diketahui bahwa kepala SMA Negeri di Rumbio Jaya telah melaksanakan supervisi, terbukti dari temuan dilapangan yang didapat peneliti para kepala sekolah mensupervisi dibidang kalender pendidikan, jadwal pelajaran, program pengajaran, rencana pembelajaran, metode mengajar, metode bertanya, penguasaan kelas, penguasaan materi, keaktifan siswa, cara menjawab pertanyaan siswa dan tidak lupa para kepala sekolah mensupervisi para wakil kepala sekolah beserta tata usaha.

Kepala sekolah SMA Negeri di Rumbio Jaya sebagai leader telah mampu menunjukkan sikap keteladanan, mampu menumbuhkan kreativitas, mampu memotivasi, mampu mengembangkan rasa tanggung jawab terhadap sekolah serta mawas diri pada guru staf tata usaha untuk mencapai visi dan tujuan sekolah. Dalam peningkatan mutu pendidikan, kepala SMA Negeri di Rumbio Jaya selalu memberi dorongan dan motivasi kepada semua warga sekolah, selain memberi dorongan dan motivasi kepada bawahan, kepala SMA Negeri di Rumbio Jaya juga memberikan bimbingan dan arahan secara baik kepada seluruh personil sekolah, dari pernyataan diatas, menurut peneliti kepala sekolah sudah mampu memberikan bimbingan terhadap para anak buahnya dengan menerapkan komunikasi yang santun dan penuh dengan kebijaksanaan untuk mengajak melaksanakan tugas-tugasnya dengan penuh tanggungjawab. Perilaku kepala sekolah menggambarkan keakraban dan suasana kekeluargaan, sehingga hal ini menjadi kesan tersendiri bagi para guru dan karyawan lainnya. Gambaran sikap kepala SMA Negeri di
Rumbio Jaya tersebut tercermin dari hasil penelitian yang mana responden mengatakan bahwa kepala SMA Negeri 01 di Rumbio Jaya Seorang leader yang beribawa dan karismatik, begitu juga perlakukannya pada bawahannya, sehingga dia sangat dihormati dan disegani oleh warga sekolah terutama oleh para sisswa, berbeda dengan ungkapan responden di SMA Negeri 02 Rumbio Jaya yang mengungkapkan bahwa kepala SMA Negeri 02 di Rumbio Jaya yang perwatakannya tegas, humoris dan social. hal ini yang membuat kepala SMA Negeri 02 di Rumbio Jaya ditakuti sekaligus disegani warga sekolahnya, terutama bagi siswa yang bandel dia sangat ditakuti dan bagi siswa berprestasi dia sangat disegani dan disukai, karena beliau tidak member batasan dalam beintraksi dengan siswanya, tetapi beliau tegas dalam menjalankan kedisiplinannya. Dalam palaksanaan peran kepemimpinan sekolah terlihat bahwa kepala SMA Negeri di Rumbio Jaya cerdas dalam memimpin anak buahnya juga mempunyai ciri yang unik untuk dalam menilai dan menentukan sikap terhadap mereka. Potensi sumber daya manusia baik dari murid guru maupun karyawan lainnya yang berkualitas, maka kepala SMA Negeri di Rumbio Jaya memberikan sebagian tugas dan tanggungjawabnya kepada bawahan dengan tujuan agar merasa turut bertanggungjawab terhadap pelaksanaan program pendidikan yang telah disusun secara bersama. Pendelegasian kewenangan dan pemberian tugas ini dilakukan berdasarkan kemampuan dan bidang keahliannya masing-masing. Berbeda dalam hal terhadap para siswa, perlakukan kepala SMA Negeri 01 Rumbio Jaya dengan karismatiknya dia mensuport dan memberi bimbingan lebih kepada siswa dengan bantuan 
guru bidang ahli siswa, kepala sekolah juga member nilai lebih dalam hal potensi yang dimiliki anak tersebut. perlakukan kepala SMA Negeri 02 Rumbio Jaya terhadap siswa yang memiliki potensi yang menonjol dia lebih melakukan pendekatan emosional, sehingga dengan karakter humorisnya dia bisa lebih menggali potensi anak tersebut, dengan sikapnya yang juga tegas dia memberi perlakuan khusus tugas pelajaran lebih untuk mengasa potensi anak. Kepemimpinan kepala SMA Negeri 01 Rumbio Jaya tergolong kepada Kepemimpinan partisipasi, gaya kepemimpinan seperti ini lebih kepada berorientasi kepada program kerja dan kinerja anggotanya. GAYA kepemimpinan kepala SMA Negeri 02 Rumbio Jaya tergolong kepada Kepemimpinan konsultasi, gaya kepemimpinan seperti ini lebih berorientasi kepada orangnya dibandingkan program kerjanya. Jiwa pemimpin yang ditunjukkan oleh kepala sekolah sangat menentukan terciptanya hubungan emosional yang dapat membangun suatu jiwa yang merasa memiliki dan bertanggung jawab atas terlaksana proses pendidikan dan pencapaian mutu pendidikan, peran kepala sekolah yang sosial menimbulkan hubungan yang erat antara guru dengan kepala sekolah dan murid dengan kepala sekolah sehingga menciptakan kenyamanan dan meningkatkan proses blajar mengajar yang baik hingga proses peningkatan mutu pendidikan berjalan sangat memuaskan.

Kepala SMA Negeri di Rumbio Jaya dalam melaksanakan perannya sebagai inovator, telah melakukan berbagai terobosan dengan melakukan pembaharuan, pada umumnya kepala sekolah melakukan inovasi dalam pelajaran, seperti kepala SMA Negeri 01 Rumbio Jaya mengembangkan pelajaran kearah loka karya dan pertanian, serta mengintruksikan kepada para guru untuk mengenbangkan cara pengajaran dengan minat anak yang umum digemari. Kepala SMA Negeri 02 Rumbio Jaya membuat inovasi pembelajaran kearah religius, dengan menargetkan anak didik hafal satu juz quran setelah tamat sekolah, minimal juz ammah (juz 30), hal ini tercermin dari sanksi bagi anak yang melanggar peraturan sekolah nereka selalu diakhir hukuman harus membaca alquran, kepala SMA Negeri 02 Rumbio Jaya lebih menekankan inovasi pembelajaran terhadap guru dari pada muridnya, sehingga mengakibatkan guru harus lebih inovatip dalam mengajar agar menumbuhkan minat anak belajar, karena temuan dilapangan menunjukkan kurangnya minat belajar anak disebabkan anak didik yang berada di SMA Negeri 02 Rumbio Jaya kebanyakan adalah anak yang tidak lulus dari sekolah pavorit, hingga menjadi anekdok bahwa sekolah SMA Negeri 02 Rumbio Jaya sebagai sekolah penampungan, dari latar belakang tersebut pengembangan inivasi dilakukan kepala sekolah supaya guru agar lebih inovatif menumbuhkan minat belajar anak, guru melakukan pembelajaran lebih menjurus kepada hobi dan kegemaran anak didik dalam prosess pengajarannya tetapi tidak lari dari acuan dan silabus pembelajaran, dengan inovasi pengajaran yang dilakukan sedikit demi sedikit membuahkan hasil dengan tergalinya potensi terpendam pada anak hingga membuat prestasi dan mengangkat mutu sekolah sekaligus mematahkan anekdot sebagai sekolah penampungan. Segi inovasi yang dilakukan kepala SMA Negeri 01 Rumbio jaya lebih berorientasi kepada program kerja dan inovasi pembelajaran lebih berorientasi kepada siswanya. Inovasi kepala SMA 
Negeri 02 Rumbio berorientasi kepada individu ataupun orang yang dipimpinnya, dalam hal pengaplikasian inovasi pendidikan, pola kerjanya berorientasi kepada siswa tetapi penekanan orientasi lebih kepada gurunya. Peran inovasi kepala sekolah sangat mendudkung terciptanya prestasi bagi peserta didik, dengan inovasi kepala sekolah dapat memudahkan dalam pengaplikasian proses blajar mengajar, sehingga menjadikannya sesuatu yang menyenangkan dan pelajaran lebih muda dipahami juga dimengerti. Peran kepala sekolah sebagai innovator pada SMA Negeri Rumbio Jaya sangat memberikan dampak positif terhadapa mutu pendidikan.

Motivasi yang diberikan oleh kepala SMA Negeri di Rumbio Jaya telah mampu membuat bawahannya mau bekerja keras dan bekerja cerdas sesuai dengan yang diharapkan. Pola motivasi yang diberikan oleh kepala sekolah SMA Negeri di Rumbio Jaya terhadap bawahannya masing-masing dengan cara berbeda-beda sesuai dengan pola masing-masing yang paling menonjol. Dua sisi penting dari motivasi yang dilakukan kepala SMA Negeri di Rumbio Jaya untuk mengambil pendekatan tidak langsung menciptakan suasana organisasi yang mendorong warganya untuk lebih produktif. Suasana ini tercipta dengan membuat sistem-sistem imbalan dan hukuman, menegakkan standar, peraturan, kebijakan yang ketat, dan pemeliharaan komunikasi.Kepala sekolah disamping memberi dorongan dan bimbingan dalam melaksanakan tugas-tugas KBM, beliau juga tidak lupa memperhatikan kesejahteraan para guru dan pegawai tata usaha, karena kebanyakan daru guru hanya berstatus kontrak yang mengakibatkan kurang loyalnya para guru dalam menjalakan tugas yang porsinya berlebih dari jam mengajar yang ditetapkan. Salah satu motivasi khusus yang diterapkan kepala sekolah adalah dengan memberikan penghargaan terhadap prestasi guru maupun siswa, sedangkan motivasi umum adlah dengan proses kenaikan pangkat baik regular dan kenaikan gaji berkala selalu tepat waktu, dana insentif disediakan yang bersumber dari dana komite sekolah. Kesejahtraan guru tetap dan guru tidak tetap di berikan tambahan dana yang bersumber dari dana komite sekolah. Guru diberi tugas untuk mengikuti pelatihan/penataran untuk meningkatkan profesional baik tingkat kabupaten/kota, propinsi ataupun nasional yang kesemuanya ini mendatangkan kesejahteraan baik secara profesional maupun dari segi materi.

Faktor-faktor penghambat pelaksanaan peran kepala sekolah dalam meningkatkan mutu pendidikan SMA Negeri di Kecamatan Rumbio Jaya Kabupaten Kampar Riau.

Kurangnya wadah pelatihan tenaga administrasi sekolah profesional. Sumber daya yang terbatas/Keterbatasan sarana dan prasarana. Kesejahteraan pendidik dan tenaga kependidikan yang belum terpenuhi. Secara keseluruhan input kulaitas siswa SMA Negeri di Kecamatan Rumbio Jaya yang relatip lemah.

\section{SIMPULAN DAN REKOMENDASI}

Kepala SMA Negeri 01 Rumbio Jaya dan Kepala SMA Negeri 02 Rumbio Jaya dalam melaksanakan tugasnya sebagai pemimpin pendidikan telah melaksanakan perannya sebagai edukator, manajer, administrastor, supervisor, leader, inovator maupun motivator. Dimana peran kepala SMA Negeri 01 Rumbio Jaya dan Kepala SMA Negeri 02 Rumbio Jaya tersebut 
secara keseluruhan sangat mewarnai pelaksanaan kegiatan pendidikan dan upaya meningkatkan mutu pendidikan di SMA Negeri di Kecamatan Rumbio Jaya. Kemudian dilihat dari perspektif kepemimpinan pendidikan, kepala SMA Negeri 01 Rumbio Jaya dan Kepala SMA Negeri 02 Rumbio Jaya dalam menjalankan keseluruhan peran yang dilakukannya baik sebagai edukator, manajer, administrastor, supervisor, leader, inovator maupun motivator. Hal ini dapat dilihat dari pola hubungan dari masing-masing anggota organisasi (antara pihak kepala sekolah, guru dan tata usaha serta seluruh komponen warga sekolah) yang baik dan benar sehingga dengan pelaksanaan peran yang baik dapat menggerakkan seluruh potensi sumber daya yang ada ke arah peningkatan mutu pendidikan dan hasilnya berbagai prestasi dapat diraih baik oleh pihak lembaga (sekolah) dan warga sekolah baik guru maupun para siswa. Peran kepala sekolah sangat berpengaruh terhadap peningkatan mutu pendidikan, dari ketujuh peran kepala SMA Negeri di Rumbio Jaya yang digunakan, peran kepala sekolah sebagai leader dan innovator yang sangat memberi dampak terhadap perkembangan mutu pendidikan kearah yang lebih baik, kedua peran tersebut adalah yang membedakan pencapaian prestasi siswa dan kemajuan siknifikan SMA Negeri Rumbio Jaya, peran kepala sekolah dibidang kepemimpinan dan inovasi yang dapat menimbulkan suatu perubahan dan pemahaman yang berdampak kepada bertambahnya keinginan guru dan siswa mencapai keberhasilan dan prestasi.

Berkaitan dengan peran kepala SMA Negeri di Kecamatan Rumbio Jaya yang telah dilaksanakan, hendaknya bisa dilakukan penelitian lebih lanjut tentang hubungan kepemimpinan dan inovasi terhadap peningkatan mutu pendidikan.

\section{DAFTAR PUSTAKA}

Danim, S. (2004). Motivasi Kepemimpinan dan Efektivitas Kelompok. Penerbit Rineka Cipta.

Departemen Pendidikan Nasional. (2007). Peraturan Menteri Pendidikan Nasional Nomor 13 tahun 2007 tentang Standar Kepala Sekolah. Jakarta: Departemen Pendidikan Nasional.

Departemen Pendidikan dan Kebudayaan, 1996-1997. Petunjuk Administrasi Sekolah Menengah Umum, Jakarta : Proyek Pembinaan Sarana Prasarana Pendidikan dan Penilaian Hasil Belajar Tahap Akhir Nasional Direktorat Jenderal Pendidikan Dasar dan Menengah Direktorat Sarana Pendidikan.

Miles, M. B. \& Hubermen, A. M., (1994). Qualitative Data Analisis, California : Sage Publication.

Mulyasa, E., (2007). Menjadi Kepala Sekolah Profesional, Bandung : PT. Remaja Rosdakarya.

Thomas \& Hartle, (2003). Educational Administration : Theory, Research, and Practice. New York : McGraw-Hill.

Umar, Jahya, 2005. Rekayasa Sistem Penilaian Dalam Rangka Meningkatkan Kualitas Pendidikan, Yogyakarta : HPI UNY. 